\title{
Power Generation Optimization in ASEAN by 2030
}

\author{
N. Agya Utama, Keiichi N. Ishihara, Tetsuo Tezuka \\ Graduate School Energy Science, Kyoto University, Kyoto, Japan \\ Email: agyautama@yahoo.co.uk
}

Received March 29, 2012; revised April 28, 2012; accepted May 13, 2012

\begin{abstract}
The vast growing economic development in South East Asia (ASEAN) region leads to the increase of energy demand particularly electricity. Almost all the ASEAN member countries are planning to develop nuclear power plant in the near future, despite having quite enormous number of renewable energy potential such as geothermal (Indonesia and Philippines), high solar radiation (between $3-5 \mathrm{~kW} / \mathrm{m}^{2} /$ day), biomass and hydro the countries still required more sophisticated and more reliable source of power for its based load such as nuclear power. Philippines has built the first nuclear power plant back in 1980 in Bataan, however the commissioning of this plant was postponed due to the political power turbulence. The question whether nuclear or renewable energy could be the best option in term of cost effectiveness will be assessed in this paper. The optimization methodology has been used by using GAMS (General Algebraic Model), the econometric based on time series (1999-2010) is used to predict the increases of national power generation up to year 2030. The increases of electricity demand is assumed to be linear with the increased country GDP (Gross Domestic Products) and population. The optimization predicted that in Malaysia, the renewable energy could be the best option, since it shows lower cost compare to the fossil fuel based power plant. Geothermal in the Philippines shows cheaper to be commissioned compare to fossil fuel and nuclear power plant. While Indonesia the cost of nuclear still not competitive enough compare to fossil fuel, mainly due to cost of subsidy.
\end{abstract}

Keywords: ASEAN; Cost Optimization; Power Generation; Renewable Energy; Nuclear

\section{The Regional Energy Supply}

Despite having more than 28,000 billion barrels of oil reserves, the member countries of ASEAN (Association of South East Asian Nations, perhaps except Brunei Darussalam) are predicted to become a net importer of oil in the next 5 - 10 years. Apart from oil reserves, the region has some other natural resources potential such as natural gas and coal, however these resources are fastly depleting due to the rapidly growing economy in this region. Anticipating to this downward movement of fossil energy resources, most countries have begun developing renewable energy and even consider developing nuclear power plants to reduce their dependence on fossil energy and in some respects to help mitigate the impact of climate change.

The reserves on natural gas, for instance in Indonesia and Malaysia alone, are proven to be more than 5.5 TCM (Terra Cubic Meter) or almost 50\% of the reserve available (over 15 TCM) in the whole Asian region. The total reserves of more than 4300 MMT (Million Metric tones) coal in Indonesia and Thailand (both bituminous and lignite) represent the biggest fossil fuel reserves in the region [1]. However, these reserves are relatively low compared to the worldwide reserves.
Indonesia is ranked fifteenth in the world coal proven reserves, much lower than China which holds the third largest coal reserve (ca 115,000 MMT). The region total final coal consumption increased from 248.7 Mtoe in 1997 to 1620 Mtoe in 2006, to meet the electricity need which gradually increased from 369 TWh in 2000 to 3600 TWh in 2010 [1].

The oil price boom in 2007-2008 was the crucial moment for policy makers in ASEAN member countries to consider reducing its dependence on fossil fuels by shifting to other renewable energy resources. According to the prediction by Asian Center of Energy (ACE) [1], the share of generation mix in the region will move towards non-oil fuels. But by 2020, almost $45 \%$ of the fuel for mix power generation in ASEAN will still be coal, followed by $40 \%$ natural gas and only less than $2.0 \%$ oil. The rest of the electricity power will be generated either by renewable energy or nuclear power [2].

Energy Planning frequently consists of three typical growth scenarios: high, low, and medium (moderate). These types of scenarios sometimes are dangerous since people generally think that the moderate scenario is the one that is most likely to happen [3]. Moreover, to a great extent, forecast errors are led by wrong growth rate expectations, [4]. Yoo [5] emphasized that although there is 
a strong relationship between electricity consumption and economic growth, it does not necessarily imply a causal relationship. The causal relationship may very well run from electricity to economic and/or economic to electricity.

Currently, most of the planning scenarios for power generation are aimed at reducing $\mathrm{CO}_{2}$ or Green House Gases (GHG), with somewhat less consideration on economic factors. Yet, it is important to show a possible future energy scenario based on its economics merits. Power generation mix which shows minimum cost required to produce electricity is still crucial, as the region is facing the situation where vast growing development (with various priority, from poverty alleviation to infrastructure development), will lead to financial constraints. The cost of generated power not only limited to fossil fuel as major mainstream concerned but also includes the expenses of investment (construction and demolition) operation and maintenance cost and last but at least, which most of the researcher are avoiding is the cost of subsidies. As reported by Koplow subsidies to the nuclear fuel cycle have often exceeded the value of the power produced, it is accounted approximately 70 to 200 per- cent of the projected value of the power [6].

This article analyse the issues using top down approach with consideration to various cost variables (such as investment cost, decommissioning cost and cost of subsidy), with the objective of finding the least cost possible in the three main developing countries in ASEAN region:
Malaysia, the Philippines and Indonesia.

\section{Methodology}

Various cost variables had been used as constrain in the model, the future electricity demand for each countries predicted by using econometric, and the optimization model has been developed by using General Algebraic Model (GAMS). As seen in Figure 1 the result on the optimization model can be compared to the government plan of electricity mix in 2030. Other variables such as GDP and population is used, the econometric model are used based on the time series data provided by government from 1999-2010.

The data on electricity consumption and production was collected from various sources [7,8], while the cost of power generation was collected from IEA and NEA [9] NREL [10] while cost of subsidies was collected from Earthtrack report [6]. The increases of cost on fuel is assumed to be 10 percent flat up to 2030 for fossil and nuclear based power plant, these increases are due to the increases of the number of power plant under or plan to be developed in the next 20 years. Moreover the cost of $\mathrm{RE}$ is assumed to be increases 5 percent, this number due to the increases of the production line in the next 20 years. The government plans for power generation mix up to 2030 was develop by accounting software model LEAP (Long Range Energy Alternative Planning). While using GAMS the cost optimization is developed. The

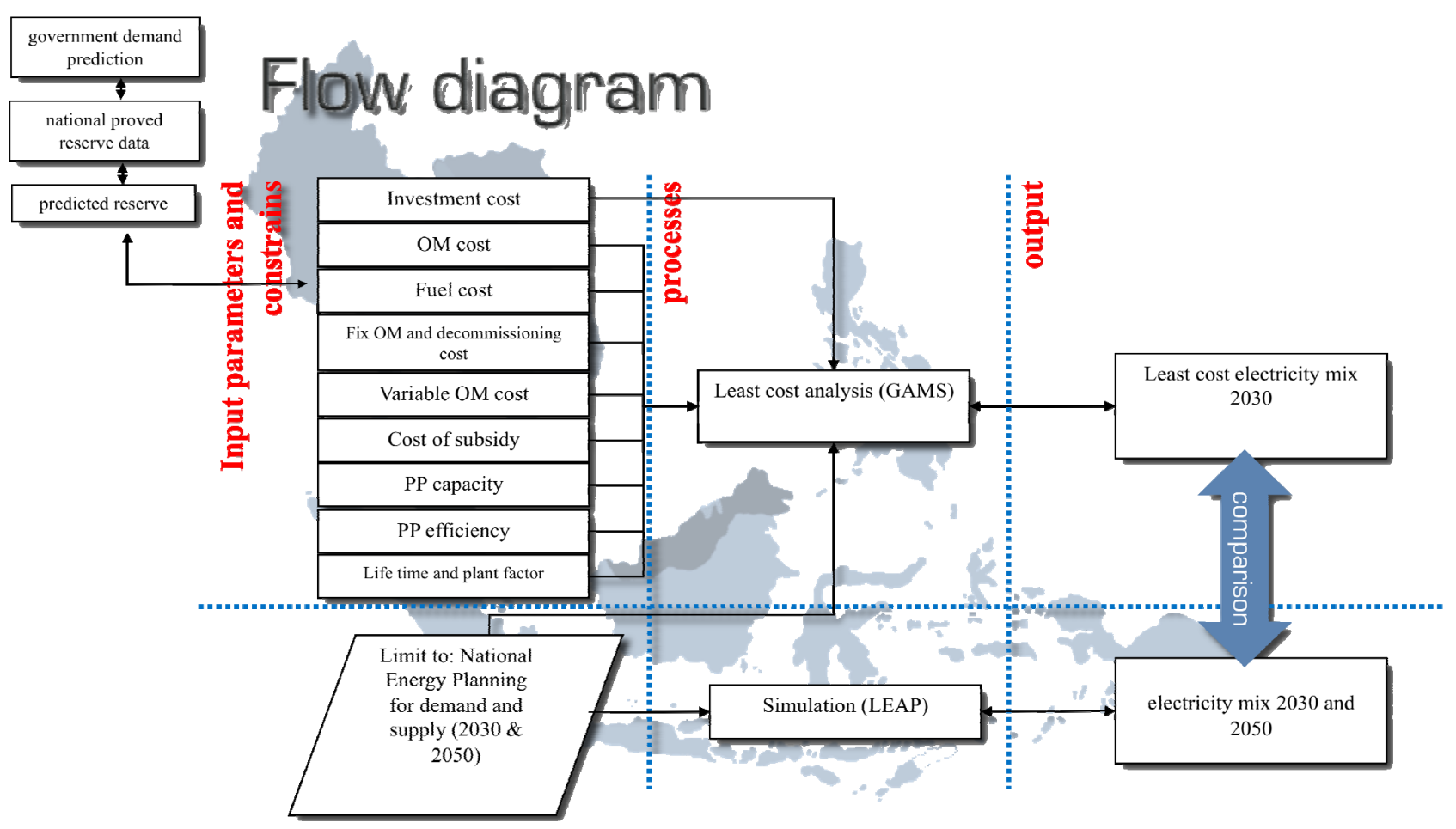

Figure 1. Flow chart process for the methology analysis. 
result of both models then compared and analyzed.

\section{Key Assumption and Parameters}

It is important to develop energy planning in the countries with vast growing economies like in the ASEAN Region, since economic and energy are strongly interrelated. Various studies show a close inter-relationships between the economic development and the energy use (particularly electricity) [11].

Some countries in the ASEAN region had produced reports on energy planning in short term (5 years) to long term (30 - 40 years). In the case of Indonesia, the National Energy Planning whichcovers 30 - 40 years in the future has passed the National Energy Council (DEN) review and was submitted to the Parliament (DPR RI) early 2011.

Meanwhile, based on APEC Report (2006), Malaysia planned to increase their electricity consumption up to 274 million TWh by 2030 [7] and will generate the power using coal, natural gas, hydro and other renewable energy. However the Plan does not yet include nuclear power plant (NPP) of which the country is planning to build and hope to commission by 2021. In fact, the Malaysian government has started to adopt nuclear policy in 2010 [12].

The Philippines Energy Plan (2009-2030) [13] shows increases in the shares of RE by 2030 and it includes low carbon energy scenario of reaching $34.2 \%$ of the total energy mix (of which 5\% from NPP). The scenario includes doubling clean and renewable energy technology, including NPP, but maintaining coal and natural gas to fill in the gap .

The study from which this article is based compares the result of the simulation model (reference) input by government energy planning for year 2030 among three countries in the ASEAN Region, namely Malaysia, the Philippines and Indonesia with cost-effectiveness using cost-optimization model, which shows the optimum power generation mix (based on minimum cost required).

In the cost-optimization model, some parameters from many resources has been used (see Figure 2 such as investment cost, operational and maintenance (OM) cost, fuel cost, fixed operational and maintenance cost, decommissioning cost, variable $\mathrm{OM}$ cost and cost of government subsides for power generation.

The model also takes into account some constraints by means of power plant capacity, power plant efficiency, power plant lifetime and plant factor (capacity factor). The definition of constraints is the limitation or boundaries where the result of the computation will refer to the limitations given by input; for instance, on power plant capacity, we use maximum capacity determined by the government for certain power plant by fuel type (e.g. capacity of hydro based power plant in 2030 for Philippines is $6.6 \mathrm{GW}$ ), then the computational process will limit of those maximum capacity given by the input.

Plant efficiency refers to how effective the power plant to convert primary energy to electricity, the plant efficiency used in the model is ranged from 20\% (geothermal) to $85 \%$ (Hydro and Nuclear). Capacity factor is a value used to express the average percentage of full capacity used over a given period of time [14]. The plant factor used in the model ranged from 30\% (Solar, biomass and wind) to $90 \%$ (Nuclear).

The assumptions on Gross Domestic Product (GDP) and population growth have been applied and the estimation calculation was based on the information given by the respective government (as seen in Figure 3). For Indonesia we assumed the population in 2030 will reach 271 million with the increase of nearly up to 8 times in GDP (compared to the 2010 GDP) see Figure 3.

Philippines assumes gaining more than double its GDP and increases its population by more than 20 million by 2030. Electrification ratio in Indonesia will reach $85 \%$ and $100 \%$ for both Malaysia and the Philippines, with the assumption that the average losses of transformation and distribution around 5\% - 10\% for all studied countries.

Malaysia's economy is expected to grow moderately over the outlook period with an annual average growth rate projected at 4.8 percent. The strongest growth will be from the industry (mainly the manufacturing sector) and the services sectors, attributing shares of 54 and 46 percent to total GDP in 2030 respectively. The electricity demand in Malaysia will increase by 4.7 percent per year over the outlook period, to reach 274 TWh in 2030. The growth in electricity demand is heavily influenced by strong demand from the industrial sector, which is projected to increase at 5.4 percent annually over the outlook period.

The reference scenario (government plan) for the Philippinees according to the analysis conducted by the government is considering green electricity mix, includeing wind power, geo-thermal and hydro as renewable resources and nuclear, as the alternative resources [13, $15]$.

For the Indonesian case, the projection shown by the National Energy Planning (NEP) was based on the recommendation from Dewan Energi Nasional (The National Energy Council). The Council's recommendations for 2030 assumed the utilization of all kinds of energy (including fossil energy and nuclear) without discrimination, reliance on renewable energy sources, with consideration with three main aspects (energy security, economic growth and environmental protection). The assumption uses estimation on $190 \mathrm{GW}$ as maximum capacity and 910 TWh generating power in 2030.

The similarities of the future power generation mix in 


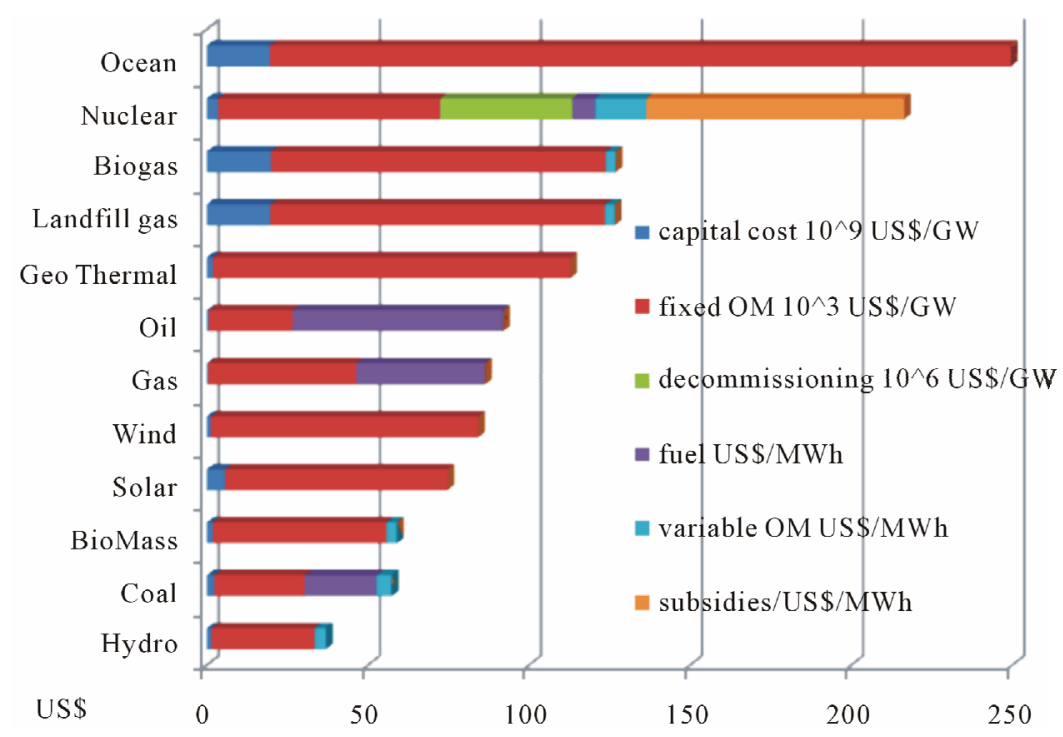

Figure 2. Inputs parameters from various life cycle variables cost.
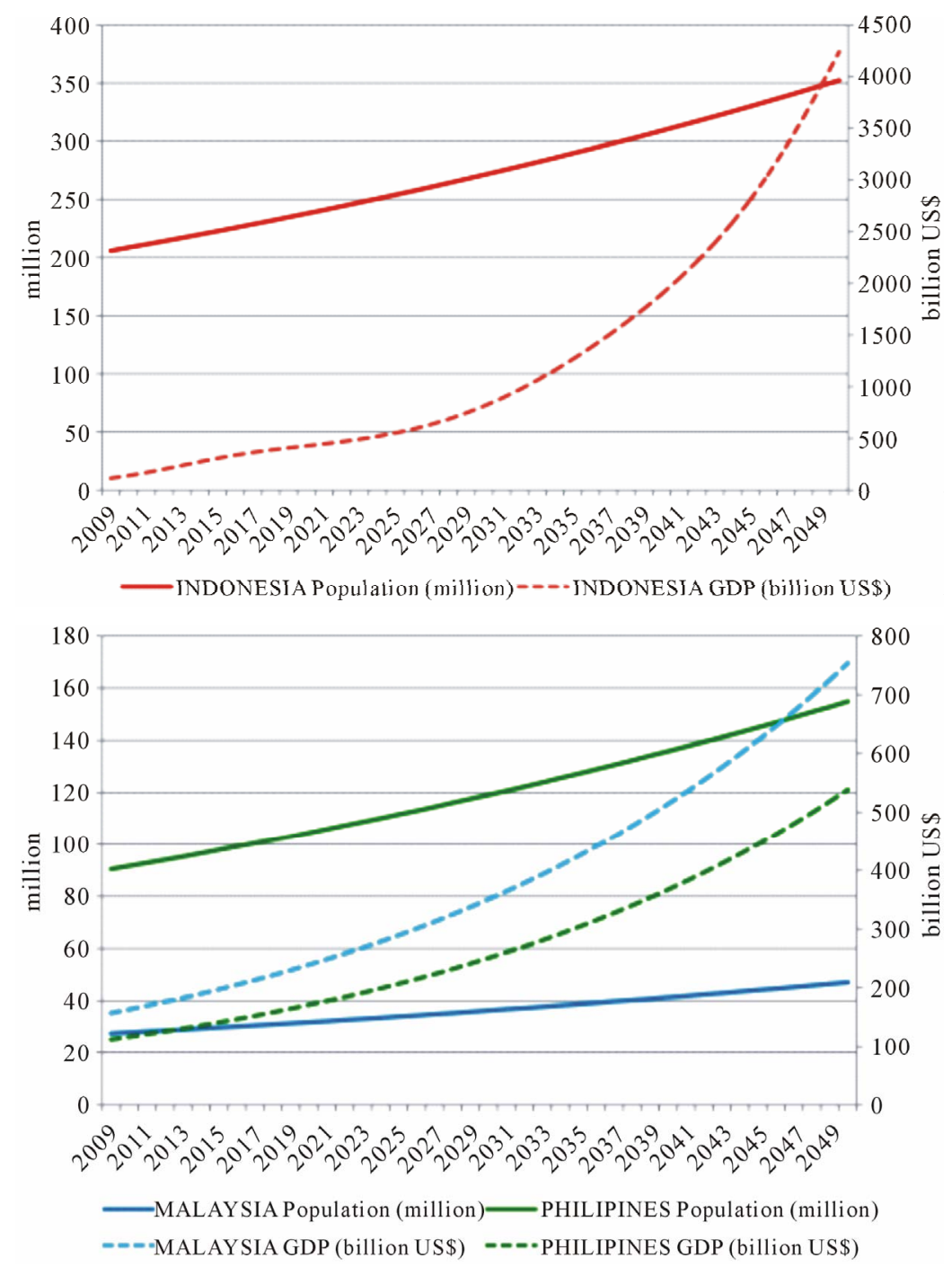

Figure 3. Key assumption for the reference and cost-optimization model; GDP and population. 
these three different countries are the willingness to install NPP in year 2030 or even earlier. Malaysia plan to have $17 \%$ NPP share in its power generation mix, while Philippines and Indonesia plan to have $14 \%$ and $4 \%$ respectively. So is the willingness to increase its renewable energy in the future without considering the economical potential (especially the cost cycle of the power generation) that may occur in the next decades is acceptable enough?

\section{Shape of the Power Generation Mix after Considering Cost Effectiveness}

Figure 4 above shows a comparison between reference (government plan) and cost-optimization for Malaysian power generation mix. The reference scenario based on Malaysian government plan shows high dependency on natural gas (NG) and coal with 33\% and 25\% respecttively, and with the combination of renewable energy such as biomass, hydro and solar, which accounted for $3 \%, 17 \%$ and $3 \%$ respectively. However, the cost-optimization result shows otherwise, the government should consider increasing portion of renewable energysince the country has little fossil energy reserve. The NPP will have higher cost compare to renewable energy in 2030, therefore it is suggested to hold the development of NPP.

The Philippines is a country which has relatively large geothermal potentials and lutilization, the government plan in 2030 shows the geothermal power plant will share approximately 10 percent to the total energy mix, but the cost efficiency model resulting otherwise. The government should increase its capacity up to $63 \%$ of its share or in more than $19 \mathrm{GW}$ in 2030 to coup with the electricity demand. The country is also famous for its strong winds, therefore the governments is planning to install wind power generation as the backbone of its electricity generation. However the cost of wind turbine shows a huge burden for the government to carry, therefore instead of increasing the wind power generation, it is suggested to increase its coal power generation up to $17 \%$ from its share (Figure 5). It is also suggested that NPP will cost higher than renewable energy and fossil fuel based power plants, therefore it is also suggested to hold its NPP in 2030 and increase the share of coal based power plant and Geothermal instead.

Indonesia is the largest archipelagic country in the world which covers 1,906,240 $\mathrm{km}^{2}$ land area and consists of 17,506 islands. Indonesia has a thriving economy at the intersection of the Pacific and Indian oceans, between Asia and Australia and it is located at $95^{\circ}$ to $141^{\circ}$ eastern longitude, and latitude between $6^{\circ}$ North and $11^{\circ} 8^{\prime}$ South 47 [16]. The length of the country from east to west is more than $5400 \mathrm{~km}$ and two third is covered by sea. The country shares land borders with Papua New Guinea, East Timor, and Malaysia. Other neighboring countries include Singapore, Philippines, Australia, and the Indian territory of the Andaman and Nicobar Islands. Current population is approximately 241 million people which make Indonesia as the world's fourth-largest country in terms of population with estimation GDP per capita USD 3550 in 2011 [17,18]. The economy grew $6 \%$ in 2011, in line with the country's 3 - 6 percent growth rate since the Asian financial crisis of the late 1990s [18].

From the perspective of cost effectiveness in Indonesia, the model revealed that it is necessary for the country to maximize its renewable energy potentials (primarily geothermal and hydropower) (see Figure 6). However the capacity of renewable energy (with the current technologies) will not be sufficientto supply the vast growing of energy demands, for which $150 \mathrm{GW}$ is required by

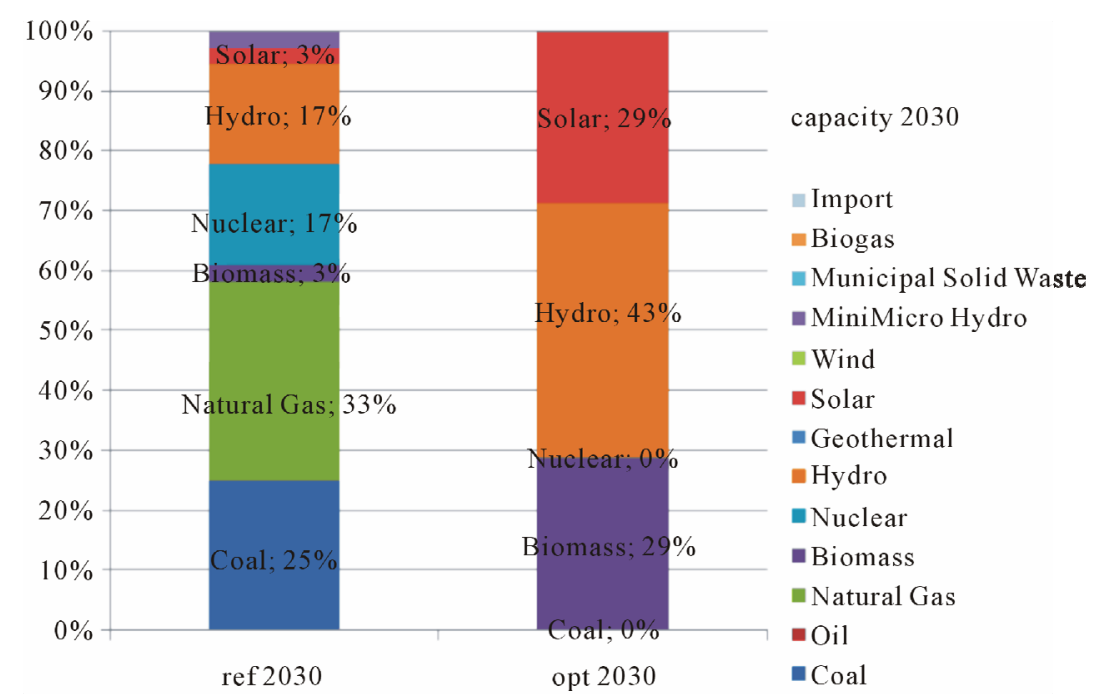

Figure 4. Proposed power generation mix with cost-optimization for Malaysia. 


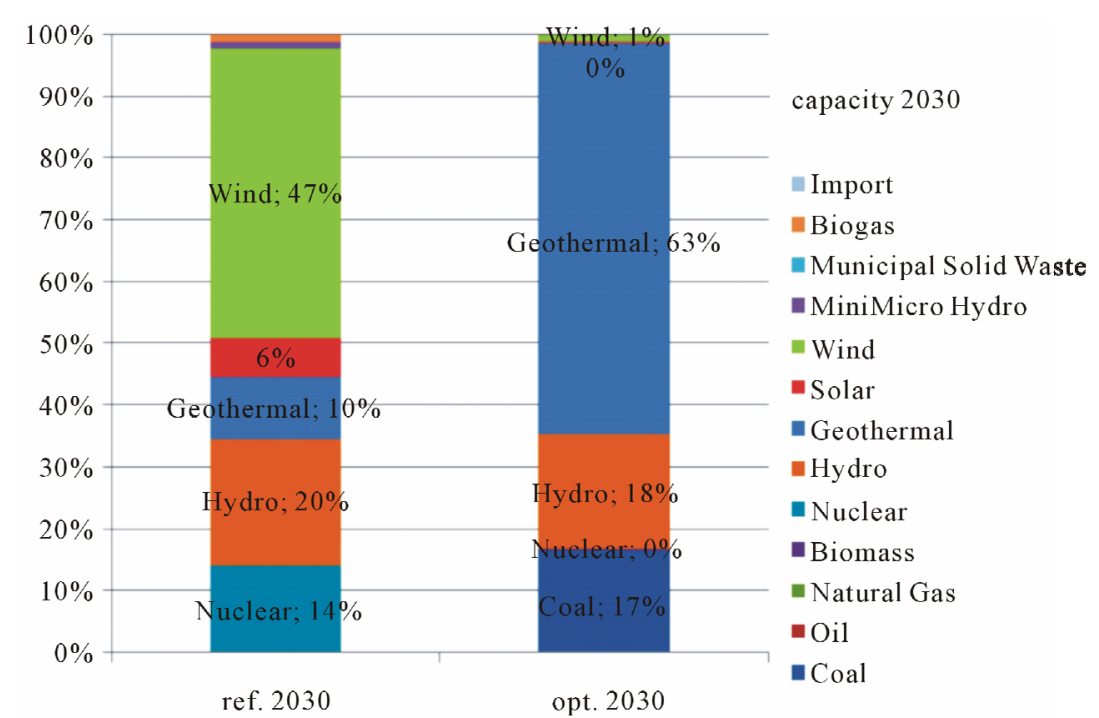

Figure 5. Philippines power generation mix reference and cost efficient 2030.

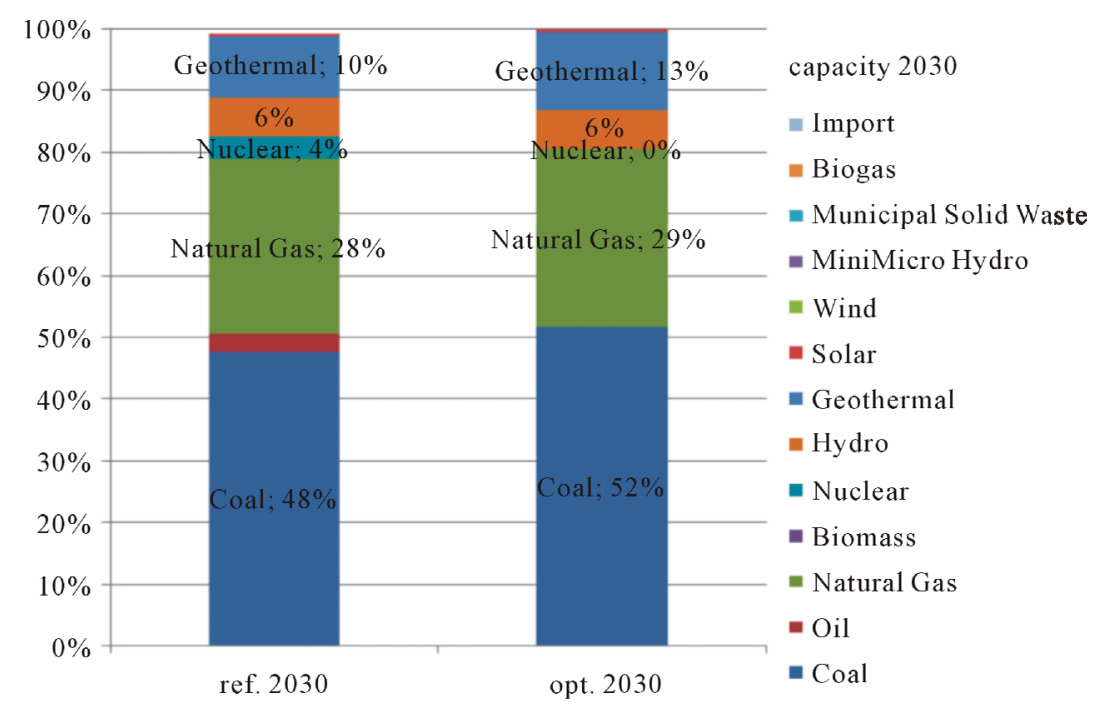

Figure 6. Proposed power generation mix with cost-optimization for Indonesia.

2030. As a result, the country is compeled to rely on fossil fuel particularly the natural gas and coal, asit is predicted that the cost of crude oil will drastically increase during the next 10 - 20 years.

As for nuclear power, according to IAEA [8] it is predicted that the cost of uranium will dramtically increase during the next 10 - 20 year as it is mentioned in the past 5 years the price of uranium already increase ten times in five years, due to vast growing number of nuclear power plants on development globally (there are up to $100 \mathrm{GWe}$ up to 375 GWe will be built in the next 10 - 20 years), which will strongly increase the demands for uranium indecades ahead.

But in the aftermath of the recent accident at Fukhusima Dai-ichi, Japan, and due to some hidden costs of NPP (such as cost of subsidies and recovering cost, de- commissioning of the plant and waste treatments which in many cases are not included in the energy generation cost calculations), the nuclear power generation will likely be much more costly. Compare to the rather competitive proce of fossil fuel which the countries has relatively high coal and natural gas reserved.

However the market condition of NPP might change if thorium were to be used for the next generation of NPP (for which the we predict to happen in the next $30-40$ years), or if the next generation of nuclear power plant comes into place, such as High Temperature Gas-cooled Reactor (HTGR), which is predicted to be commercialized by 2030 and its price is cheaper by one third compared to the current nuclear reactor generation [19]. In regards with coal which the price increases between 50\% $125 \%$ from 2003-2006 these relatively high reserve yet 
limited is being considered in the calculation. In Indonesia the prediction of 5.5 billion tonnes oil eq. of coal reserve will last up to year 2025 with the current production rate (155 million tonnes oil eq. and expeceted to increase up to 439 million oil eq. in 2020). With the current ratio of 1 to 4.5 for domestic and export use the country will rely on imported coal in year 2025 onward, the model suggested to increase the domestic use rather than exporting it. Similar condition with natural gas, even the domestic and export tratio reatively similar (50: 50) the trend on increasing export is high, as the model alos suggested to increase the use of NG.

On the other hand, the shares of renewable energy in Indonesia will definitely increase if the efficiency of to convert the resources to energy is increasing. Inline with the development of high efficiency technology in order to reduce cost of transformation and loss decentralized type power generations is necessary (since the country consist of thousand island), decentralized RE technology such as Concentrated Solar Power (CSP), Solar home system (SHS), biofuel/biodiesel small refinary in the next 30 - 40 years.

We believe that the analysis using the model discussed in this article will be of benefit to the policy maker sin considering what kind of power generation mix suitable for the country in the next 10 - 20 years or even longer term (>30 years), taking into account the life cycle cost of various power plants from fossil energy based, renewables to nuclear energy.

The model also suggested that from present to 2030 the cost of renewable energy technology will gradually reduced and the cost of fossil fuel and uranium will increase. The combination for optimum power generation mixture based on cost shows some countries, which have enough fossil fuel, should utilize its resources (such as Indonesia for coal and NG and Philippines for coal) as well as maximize its renewable energy potential (Geothermal, Wind and Solar). Rather than continue planning to develop NPP based on current technology such as Boiled Water Reactor (BWR) and Pressurized Water reactor (PWR) technology. It is necessary to develop the model up to year 2050, which author think that nuclear may be one of the possible options for the region, therefore some necessary acts for acknowledging and learning the new technology of NPP such as policy and human resources is important. Other stories will be tremendous energy efficient measure in order to reduce the high demand of electricity demand in the next 20 - 40 years.

\section{REFERENCES}

[1] ASEAN Center for Energy (ACE), "Electricity \& devel- opment in ASEAN," ASEAN Energy Bulletin, Vol. 9, 2005, pp. 3-4.

[2] International Energy Agency (IEA), "Energy Statistic of Non-OECD Countries,” IEA Statistic, International Energy Agency, 2008

[3] W. Soontornrangson, D. G. Evans, R. J. Fuller and D. F. Stewart, "Scenario Planning for Electricity Supply," Energy Policy, Vol. 31, No. 15, 2003, pp. 1647-1659.

[4] H. Linderoth, "Forecast Errors in IEA-Countries' Energy Consumption,” Energy Policy, Vol. 30, 2002, pp. 53-61

[5] S. H. Yoo, "The Causal Relationship between Electricity Consumption \& Economic Growth in the ASEAN Countries,” Energy Policy, Vol. 34, 2006, pp. 3573-3582

[6] D. Koplow, "Nuclear Power: Still Not Viable without Subsidies,” Union of Concerned Scientists, 2011.

[7] Asia Pacific Economic Cooperation (APEC), "Malaysia, APEC Energy Demand and Supply Outlook,” 2006. http://www.ieej.or.jp/aperc/2006pdf/Outlook2006//ER_M alaysia.pdf

[8] International Atomic Energy Agency (IAEA), "International Status and Prospects of Nuclear Power,” 2008

[9] International Energy Agency (IEA) and Nuclear Energy Agency (NAE), "Projected Costs of Generating Electricity,” 2010.

[10] R. Tidball, J. Bluestein, N. Rodriguez and S. Knoke, "Cost and Performance Assumptions for Modeling Electricity Generation Technologies,” National Renewable Energy Laboratory (NREL), 2010.

[11] N. A. Utama, K. N. Ishihara, Q. Zhang and T. Tezuka, "2050 ASEAN Electricity Demand: Case Study in Indonesiaand Cambodia, Zero-Carbon Energy Kyoto 2010: Green Energy and Technology,” Springer, Berlin, 2011

[12] Ministry of Science, Technology and Innovation, Malaysia, "Update on Nuclear Energy Programme in Malaysia," Integration Workshop on Advance Nuclear Reactor, Vienna, 2011.

[13] Department of Energy Philippines, "Philippines Energy Plan,” 2011.

[14] Energy Dictionary Capacity Factor or Plant Factor, 2011. http://www.energyvortex.com/energydictionary/EnergyV ortex.htm\#capacity_factor_plant_factor.html

[15] Department of Energy Philippines, "Renewable Energy Policy,” Department of Energy, 2011.

[16] Badan Pusat Statistik Indonesia, "Statistical Yearbook of Indonesia 2011,” Jakarta, 2011

[17] Indonesian Companies News, "National Income per Capita," 2011.

http://indonesiacompanynews.wordpress.com/2011/08/06 /akhir-2011-pendapatan-per-kapita-us-3-600/search

[18] Direktorat Diseminasi Statistik, "BPS, Data Strategis BPS, CV,” Nasional Indah, Jakarta, 2010.

[19] M. Ogawa, “Author Personal Communication,” Japan Atomic Energy Agency (JAEA), 2011. 